\title{
UNIVERSITY OF SIENA
}

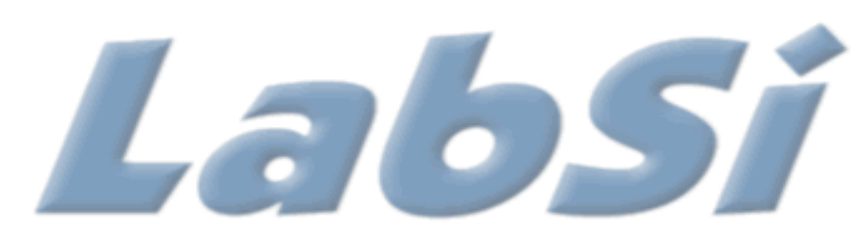

EXPERIMENTAL ECONOMICS LABORATORY

\author{
Alessandro Innocenti \\ Virtual Reality Experiments in Economics
}

November 2015

\section{LABSI WORKING PAPERS}

N. $49 / 2015$ 


\title{
Virtual reality experiments in economics
}

Alessandro Innocenti

University of Siena

\begin{abstract}
The paper provides a review of research using virtual reality as a tool in experimental economics. It addresses the question of whether behavior in virtual environments is a valuable source of empirical evidence for economists. A typology of virtual reality experiments based on the difference between low-immersive (LIVE) and high-immersive virtual environments (HIVE) is offered. It is argued that virtual reality experiments are framed field experiments, which allow testing the effect of contextual cues on economic decision-making under the strict control of the experimenter. This feature enhances replicability and attenuates the context-free illusion that represents an important limitation of the standard laboratory approach in economics.
\end{abstract}

Keywords: virtual reality, experimental economics, laboratory methods, virtual worlds, immersive environments.

JEL classification: B41, C90, C93 


\section{Introduction}

Laboratory experiments were first proposed as tools for economists nearly 70 years ago. Over this span of time they have been increasingly used to improve our understanding of economic behavior and investigate market efficiency. As a result, it is not controversial today that simulating and analyzing choices taken under artificial and controlled conditions is useful for economists to such an extent that experimental methods in economics have become a reference for comparison and validation of disciplines like psychology, which originated as experimental sciences (Hertwig and Ortmann 2001)

Nevertheless, the evolution of the discipline has been anything but straightforward by giving rise to a vigorous debate that have put continually under scrutiny methods and principles of laboratory research in economics (Guala 2005). This history, which owes its inception to the laboratory tests of Von Neumann and Morgenstern's (1944) models of strategic interaction, and its key turning points to Vernon Smith's (1962) representation of markets as experimental microeconomic systems and Tversky and Kahneman's (1975) foundation of behavioral economics, challenged and modified the fundamentals of economics by focusing on the validity of the economic rationality hypothesis. As a result, the main approach to experimentation in economics aimed at verifying the behavioral implications of abstract models in very stylized decision tasks rather than addressing the issue if laboratory behavior generalizes to the real world.

More recently, however, the debate on the application of laboratory methods to economics has progressively shifted from the content to the context of experiments. On one hand, it has been argued that context-free experiments are an elusive goal because laboratory is not a socially neutral framework but an institution per se with its own formal and informal, explicit and tacit, rules (Loewenstein 1999). ${ }^{1}$ On the other hand, the behavioral and cognitive approaches to economics have contended that it is not appropriate to draw conclusion about the validity of theories from experiments without taking into account how context affects behavior (Harrison and List 2004,

\footnotetext{
1 "Many experimental economists seem to view their enterprise as akin to silicon chip production. Subjects are removed from all familiar contextual cues. Like the characters 'thing one' and 'thing two' in Dr. Suess' Cat in the Hat, buyers and sellers become 'persons A and B, and all other information that might make the situation familiar and provide a clue about how to behave is removed. The desire to expunge context is reminiscent of a movement among behaviourist psychologists in the middle of this century, at the peak of which some researchers conducted experiments in 'context free' temperature and sound-regulated white egg-shaped enclosures. The context-free experiment is, of course, an elusive goal. An egg-shaped cage provides the same amount of context, albeit somewhat more alien, as any other environment" (Loewenstein 1999: F30)
} 
Levitt and List 2007). ${ }^{2}$ Indeed, a major tenet of cognitive psychology is that all forms of thinking and problem solving are context-dependent and that to test decision models it is necessary to remind and to evoke in the laboratory social and environmental cues, which may activate emotions and associations and trigger the use of field heuristics (Loewenstein 1999).

These arguments led Harrison and List (2004), which endorse field experiments to check the validity of laboratory findings when context matters, to propose a taxonomy that differentiates natural from framed field experiments, being the latter those in which "the field context is embodied in either the commodity, the task, or information set that the subjects can use" (Harrison and List 2007: 1014). A recent approach to embody the field in the lab is offered by virtual reality experiments, which can be considered proper framed field experiments, since they provide computer-controlled sensory contexts in which users are immersed under the full control of the experimenter.

The main argument of this paper is that, by creating controlled environments in which individuals decide and interact, virtual reality may contribute to offset the context-free illusion affecting the main approach to laboratory experimentation in economics. To support this point, the following pages present the research using virtual reality in order to assess if it can contribute to check the empirical validity of economic theories and, by rephrasing Harrison and List (2007: 1013), to verify if successful heuristics that evolve in certain virtual reality environments travel to field and lab settings.

The next section 2 provides some definitions and a typology of virtual reality experiments based on the difference between low-immersive virtual environments (LIVE) and high-immersive virtual environments (HIVE). Section 3 surveys experiments that apply virtual reality to the test of economic theories by addressing, first, the question if subjects' behavior differs between laboratory and virtual worlds and, then, if virtual environments can provide significant contexts for economic decision-making. The final section summarizes strengths and weaknesses of virtual reality experiments in economics and contains some suggestions for future research.

\footnotetext{
2 "This approach omits the context in which the stressor is normally considered by the subject. In the 'real world' the individual is paying attention not only to the stressor, but also to the environment around him and various other influences. In this sense, individuals have natural tools to help cope with several influences, whereas these natural tools are not available to individuals in the lab, and thus the full effect of the stressor is not being observed." (Harrison and List 2007: 1033)
} 


\section{Defining Virtual Reality Experiments}

Virtual reality is a powerful technique to simulate situations and tasks that allows an accurate control of the state experienced by users. Technically, virtual reality is a computergenerated real-time setting where individuals act in a simulated environment. It is a system composed by hardware and software that creates artificial locations through an interface which stimulates one or more senses. The digitally generated space is such that users' movements are tracked and environs are displayed in synchrony with users' actions.

The virtual reality technology can be applied to two types of environments that are differentiated by the degree of users' immersion.

The first types are low-immersive virtual environments (LIVE), which are computer screenbased renderings of real environments or virtual worlds, such as Second Life, World of Warcraft, Kaneva, The Sims, in which users interact each other through digital models called avatars embodying their virtual selves.

The second types are high-immersive virtual environments (HIVE), which employ specialized displays as Cave Automatic Virtual Environment that are enclosed boxes in which the user is shown images projected on multiple interior screens, head-mounted displays, such as Oculus Rift, Samsung Gear VR or Google Cardboard, or augmented or mixed reality devices, like Microsoft Holographic and HoloLens headsets. In these settings, users' senses are dominated by the technical equipment to a degree related to the adoption of devices such as headphones, body trackers, gloves or touch controller, the extent of view field, the quality of rendering, and the speed of the interaction with virtual domains.

The key element that differentiates virtual reality experiments from standard laboratory tests is the higher level of immersion, a factor which can provide original evidence for a variety of reasons.

The first is related to the theory of ecological rationality (Gigerenzer 1999, Smith 2003), according to which decision making is dependent on the cognitive constraints of decision makers. In order to predict, describe and explain choices, it is necessary to assess carefully the process of individual perception by taking into account the decision environment and the impact of naturally occurring cues, contextual features or pattern recognitions. Ecological rationality is defined as the adaptation to specific environments in order to enhance individual ecological fitness. Thus, cognitive processes are efficient only in relation to specific conditions, while they may be 
inappropriate in other situations. In virtual reality settings, differently from standard laboratories, individuals can be shown naturalistic details such as "to generate cues that are sufficiently natural and familiar that decisions will be significantly more like those that would be generated in the field with sufficient expertise." (Fiore et al. 2009: 69).

The second reason for adopting virtual reality is to experimentally investigate the heuristics adopted by individuals to reduce task complexity and cognitive load. By injecting in artificial environments frames and cues presents in real domains, virtual reality experiments can validly support the main purpose of behavioral economics, that is concerned with the effect of psychological and emotional factors on decision-making (Camerer and Loewenstein 2003). By being immerse in artificial environments, individuals responds to the virtual stimuli as if they were real and can adopt the heuristically driven behavior induced by the messages (Slater et al. 1994, Biocca et al. 2003, Sanchez-Vives and Slater 2005).

Thirdly, the immersion in virtual settings can enhance the feeling of co-presence, which occurs when individuals treat other digital agents as if they were real human beings (Blascovich et al., 2001). Most virtual reality research on social interaction was conducted in virtual worlds as Second Life, in which users form communities and learn by experience how to interact. These characteristics make Second Life a socio-economic environment per se, in which it is also possible to investigate if behavior in virtual reality mimics actual economic behavior (Castronova et al. 2009, Bloomfield and Choo 2011), to analyze social cognition (Bainbridge 2007) or to implement business education (Bloomfield 2009). Thus it is not surprising that the pros and cons of Second Life as scenery for economic experiments have been carefully scrutinized (Bainbridge 2007, Chesney et al. 2007, Duffy 2011, Fiedler et al. 2011, Greiner et al. 2014).

Second Life's main practical advantage is that it makes available graphic tools and software to build virtual laboratories, where subjects may be recruited, instructed and incentivized. Second Life allows replicating standard laboratories with great flexibility, by achieving a tighter control and providing easier access to a great number and variety of subjects. Virtual worlds give access to a subject pool that is far more diverse than student populations in many aspects, i.e., education, age, background, ethnicity, and nationality, but they also allow submitting tests to the standard lab population composed by students or to specific classes of individuals or experts in some field domain.

Design implementation can be carried out easily and conveniently. Both pen-and-paper and computerized experiments can be reproduced accurately and economically. More importantly, the 
environment offer greater realism and may include richer contexts than physical laboratory, by providing cues and hints mimicking those occurring in the real world. In virtual worlds nothing prevents from repeating experiments over long periods with the same set of individuals or to allow or not allow interaction among subjects. Verbal and nonverbal communication between experimenters and subjects and among subjects can rely on a variety of channels (chat, voice, message boards, and screen boxes) that can also be activated simultaneously, privately or publicly. If necessary, participants may be assembled in the same virtual location to read instructions, as it normally happens in standard laboratories, and post-experiment surveys are easily collectable by checking in real time data collection and comprehension failures. Finally, incentives can be provided through virtual money (Linden dollars), that are convertible to real currency at Lindex, an official currency exchange, or at third party exchanges, or by assigning virtual goods, which are available in virtual markets and shopping malls.

On the other hand, anonymity, virtual identity and their entertaining nature present potential drawbacks of experiments conducted in virtual worlds.

Firstly, the impossibility to physically observe experimental subjects may represent an invalidating factor. Users may falsify their identity and state, participate multiple times or act in groups by changing avatars, e-mail or IP address (Chesney et al. 2007). They may unexpectedly disappear attracted by other web activities offering greater rewards (Duffy 2011). These issues may seriously affect the generalization from results obtained in virtual worlds that can depend on selection biases hard to remove (Harrison et al. 2011).

Secondly, the use of avatars can be a source of biased behavior. Avatar-based communication has been criticized for being unnatural (Koch 2004) and the creation of an artificial identity can be instrumental to users' interests or expectations. ${ }^{3}$ Significantly, Yee and Bailenson (2007) show how the change of the physical appearance of avatars can have a substantial and instantaneous effect on behavior in virtual environments. ${ }^{4}$ In general, avatars are cast in roles and users may act in accordance with his misperceptions of these roles.

Thirdly, it may be more difficult than in the lab to convince participants that they are part of a scientific experiment. Virtual worlds project a game-like atmosphere in which users may see

\footnotetext{
3 "An important purpose for virtual worlds is to create an alternate life, so that differences from one's own life and characteristics, projected and self-reported in virtual worlds, might be expected to be false" (Harrison et al. 2011: 92).

4 "The set of studies presented in this paper makes clear that our self-representations have a significant and instantaneous impact on our behavior. The appearances of our avatars shape how we interact with others. As we choose our self-representations in virtual environments, our self-representations shape our behaviors in turn." (Yee and Bailenson 2007: 287).
} 
himself "matching wits" against other subjects or the experimenter. The same incentive effect may be biased by the fact that Linden dollars are not measured by price indexes, which causes Second Life residents to show a drastic overvaluation of virtual money. (Greiner et al. 2014)

These criticisms are suitable for the low immersive condition and, particularly, for virtual worlds, while appear less pertinent for the high immersive one, in which subjects are physically present in the laboratory and technical equipment assures a full control on users' experience. The key question for HIVE is whether they can be considered useful settings for conducting experiments. Are decisions of subjects isolated from reality by helmets or caves responsive to the design created by the experimenter? This issue can be discussed in term of the concepts of immersion and presence. The isolation experienced in HIVE allows people focusing solely on experimental stimuli, by reinforcing the effect of monetary incentives that are the main requisite for the validity of findings in standard economic laboratories. Subjects' immersion in virtual environments, which dominates their perception, does not prevent them from being fully active and cognitively engaged during exposure (Fox and Bailenson 2009, Lee et al. 2009). This condition enhances the sense of presence to the point that "responses should be considered at every level, from unconscious physiological behaviours through automatic reactions, and from conscious volitional behaviours through to cognitive processing - including the reporting of the sense of 'being there'" (Sanchez-Vives and Slater 2005: 338).

The feeling of presence allows shedding light on cognitive processes typically neglected in experiments in which subjects play strategic games or assess probabilistic outcomes as the outcome of conscious and deliberate reasoning. Behavior in LIVE and HIVE can be analyzed like the outcome of field experiments in which the context is entirely embodied, and consequently controlled, in the experimental design. It is just this feature that represents the main difference between virtual reality and field or laboratory experiments and that inform most research work that is discussed in the following section.

\section{Virtual Reality Economic Experiments}

It is not surprising that most economic experiments in virtual reality are conducted in LIVE and particularly in Second Life, which provides a set of ready-to-use tools. It is also expected that most research directly addresses the question if behavior "maps" from the lab to the virtual by replicating experiments conducted in standard laboratories. If this may not be necessarily the best 
approach to appraise the significance of a new method, the emphasis on comparison is a consequence of the high degree of innovation characterizing virtual reality. However, it should first be taken into account that the full appraisal of its potential role in experimental economics still depends on the implementation of the more innovative HIVE, whose introduction is still in its infancy.

To provide a review of the state of the art, it is useful to divide research works focused on methodological issues (section 3.1) from those introducing explicitly contextual elements in the experimental design (section 3.2). The papers surveyed below are selected on the basis of two features. Firstly, they concern economic experiments conducted in virtual reality environments and, secondly, tests in which participants are rewarded with monetary incentives. These selection criteria exclude online experiments, in which subjects are recruited on the Internet to participate in standard economic experiments (Anderhub et al. 2001, Eckel and Wilson 2006, Charness et al. 2007), and studies using virtual worlds as venues for proper field experiments (Nicklish and Salz 2008, Bloomfield 2009, Castronova et al. 2009, Fiedler 2011, De Sousa and Munro 2012).

\subsection{Does virtual world behavior map to the laboratory?}

Firstly and mostly, the question addressed by economists in virtual worlds is whether virtual reality experiments replicate the results of standard laboratories rather than if and how individual behavior differs between real and virtual environments.

Chesney et al. (2007) are the first to investigate if "virtual behaviour conforms to established results generated in conventional experimentation" (p. 621). They submit to Second Life residents a set of strategic games to analyze how their choices replicate previous laboratory findings. Subjects are casually recruited in Second Life locations and gathered in a virtual building with restricted access, equipped with virtual objects and tools very similar to computerized laboratories. Instructions and post-experiment surveys are delivered in written form and payments are made in Linden dollars just after the experiment. A close similarity between virtual and laboratory settings is found in four out of five games. The only exception is given by the dictator game, in which Second Life users exhibit a slightly greater degree of altruistic giving than laboratory subjects, which the authors attribute to the experimenter demand effect, possibly triggered by the two-way communication via private instant messaging. Chesney et al. (2007) conclude that "virtual world economic phenomena are based on similar behavioural regularities observed in standard economic 
settings and can be tested experimentally within the virtual environment", although it may be limited by the absence of physical presence that in virtual experiments may preclude "involuntary non-verbal communication, that reveals emotional states" (Chesney et al. 2007: 632).

Analogous results are provided in a within-subject experiment by Spann et al. (2007), which test dictator game in the virtual World of Warcraft and compare it to an online experiment. The virtual treatment confirms the statistically significant greater degree of altruism, which is found to be inversely correlated with the self-reported feeling of being present assessed by post-experiment questionnaires. These findings lead Spann et al. (2007) to claim that a higher degree of immersion may enhance the external validity of virtual reality experiments.

In contrast, Füllbrunn et al. (2011) provide divergent evidence in a trust game, ${ }^{5}$ which is submitted in Second Life to users' avatars and in a physical laboratory to students. Experimental results show that sent amounts are lower, returned amounts are higher and trustees' choices are more erratic in virtual reality than in the laboratory. The authors attribute these outcomes to the social structure of Second Life that is defined an informal, "still evolving" or even "capricious" society, though also a cooperative and trustworthy environment. However, it seems plausible that a sort of experimenter demand effect is at work in Füllbrunn et al.'s virtual setting. Although the procedure is strictly double-blind, the difference between the two locations, an entertainment arena in Second Life and a university cafeteria as the lab, and between the monitors recruiting participants, a fancy avatar and a student assistant respectively, might also justify the divergence between the treatments.

The comparison between virtual and laboratory experiments is extended to the ultimatum game $^{6}$ by Greiner et al. (2014), whose design examines the effect of communication with or without face-to-face interaction in Second Life vs. the lab. They find that more face-to-face communication increases offers and acceptances in the laboratory but not in the virtual world, where subjectsavatars behave more cooperatively across all treatments. Although Greiner and colleagues argue that differences may be due to the mere effect of belonging to a virtual world, they conclude that "Had Werner Güth conducted his seminal 1982 study of the Ultimatum Game in the virtual world Second Life, his conclusions about deviations of behavior from subgame-perfect homo

\footnotetext{
${ }^{5}$ In the trust game, a first mover (trustor) sends an amount out of an initial endowment to a second mover (trustee). Any amount not sent to the trustee is kept by the trustor. The amount sent is multiplied by 3 by the experimenter and the trustee then chooses to return any part of the received money back to the trustor.

${ }^{6}$ In the ultimatum game, the proposer makes an offer how to split a received endowment with the responder, who then decides if to accept or to reject the offer. In case of acceptance, the endowment is distributed as proposed, in case of reject both players get nothing.
} 
oeconomicus play would not have been different." (Greiner et al. 2014: 381) They also notices that comparability across experimental methods may be affected by discrepancies in the subjective values attached to virtual Linden and to U.S. dollars and by potentially uncontrollable selection biases in the virtual subject pool.

An original contribution in the same direction is offered by Duffy (2011), who provides the report of his own experience as participant in a virtual reality experiment. ${ }^{7} \mathrm{He}$ points out how individual perception of virtual laboratories can be negatively affected by the anonymity of avatars, which may generate a credibility problem that may alter the comparison with the laboratory. ${ }^{8}$ This issue, which also concerns online experiments, can be even worsened by the game-like atmosphere possibly characterizing virtual worlds. It may also explain the propensity to lie on personal traits, such as age, gender, education, typical of web communities. This problem does, however, not apply when virtual environments are specifically designed for the experiment.

Apart these concerns on subjects' identity, this first set of researches provides support for a close parallelism between virtual world and laboratory experimentation. The key difference seems to be caused more by the intrinsic social nature of Second Life, which has a direct impact on subjects' behavior and can be manipulated by using suggestive locations or by "teleporting" users, with effects difficult to disentangle by other environmental parameters. In this light, Second Life appears an appropriate setting for particular types of framed field experiments (Harrison and List 2004: 1014) in which the field context is embodied in its rules and norms of social interaction. This implies that the effects of interpersonal relations and communication on economic behavior can be a direct object of experimentation in virtual worlds, but also that to full appraise the validity of LIVE is necessary to analyze the effect of settings specifically created and tailored to suit experimenter's purposes.

\subsection{Can virtual environments provide context?}

The dominant approach to conduct virtual reality economic experiments is the introduction of specifically provided environmental cues in virtual worlds or in stylized virtual simulations of economic settings.

\footnotetext{
${ }^{7}$ The experiment is described in Atlas (2008).

8 "The absence of other experimental subjects does lead me to question whether the other player is real, whether those other participants have been given the same instructions (public information), and whether the environment is completely controlled by the experimenters who are playing the role of the other player." (Duffy 2011: 60)
} 
A set of papers testing the one-shot trust game adopts this approach. Atlas and Putterman (2011) investigate the effect of visual cues, Fiedler and Haruvy (2009), Fiedler (2009) and Fiedler et al. (2011) the influence of communication and social distance.

Atlas and Putterman (2011) host subjects recruited on Second Life in a specifically designed virtual laboratory, which simulates a physical one with individual rooms with avatars sat in front of the screen. Their design replicates the field experiment of Bateson, Nettle and Roberts (2006) on the relations between contributions to an honesty box and the feeling of being watched by pics of staring eyes. They project similar pics and instructions on the virtual lab room's ${ }^{9}$ and introduce two additional textual cues, respectively suggesting cooperative and competitive behavior. In the visual treatments, Atlas and Putterman (2011) find that the amounts sent by trustors is significantly increased by the cue of being watched to a degree similar to Bateson et al. (2006), while trustees are significantly more trustworthy, although their decision appears more affected by received amounts than by cues. Interestingly, visual hints result more effective than textual ones in enhancing cooperation while the reverse is true for the competition-enhancing cues, by providing support to the hypothesis that being immersed creates a sense of presence eliciting not only context-aware responses, but also unconscious reactions.

On the other hand, virtual worlds are structured networks where the effect of explicit social cues can be analyzed to assess the differences between individual and collective choices (Charness and Sutter 2012) or the patterns of group decision making (Kugler et al. 2012) without compromising real-world anonymity. This is the object of the experiments conducted by Fiedler (2009), Fiedler and Haruvy (2009) and Fiedler et al. (2011) on the effect of communication in the trust game. Fiedler (2009) compares computer mediated communication in Second Life (audio) and in Skype (text chat) by finding that cheap talk increases significantly trust propensity (the amount sent by trustors) but not trustworthy propensity (the amount returned by trustees). Fiedler and Haruvy (2009) show that avatar-based communication among students increases significantly only the amount sent by trustors with respect to treatments with no communication and communication among Second Life residents. Finally, Fiedler et al. (2011) try to elicit the embodied social presence characterizing virtual worlds (Mennecke et al. 2011). They submit trust game on the web to Second

\footnotetext{
${ }^{9}$ It is interesting to note that subjects' visual field is under the strict control of the experimenter; "One could vary what pictures hang on the wall of a brick-and-mortar lab room also. However, the virtual environment makes it easier to experiment with different placements, sizes, and lighting, to rule out the possibility of prospective subjects noticing changes being made, and to assign subjects to rooms having one or another photo or none with no possibility of seeing the other rooms (thanks to travel by "teleportation"). More importantly, perhaps, the specific visual manipulations we tried only scratch the surface of what is possible in this medium, so that our treatments might be compared to taking a new vehicle for a quite modest test drive." (Atlas and Putterman 2011: 60)
} 
Life residents and in a conventional laboratory to university students using Second Life as a platform. The treatment with partner selection is played by groups composed by one trustor and two trustees. Before playing the game, the trustor is allowed to chat on various topics with one trustee, who is located in the same room. Then, the trustor has to choose if to play the trust game with this trustee or with the other anonymous trustee located in a different room. In the first case, the amount sent by the trustor to the trustee is multiplied by 2 , while in the second case by 3 or 4 . The control treatment replicates the standard trust game played anonymously by pairs without communication. Unsurprisingly, findings show that social distance, measured by avatars' room location and communication, dominates the effect of monetary incentives by causing a loss of efficiency, but Second Life residents exhibit greater dependence on social distance, lower trust propensity and higher trustworthiness than university students by confirming how an endogenously generated social institution like Second Life influences subjects' behavior.

It is exactly this feature that induces Al-Ubaidly et al. (2014) to consider Second Life as a proxy for social institutions in which to conduct a framed field experiment on the natural resource curse. The authors claim that "the visceral, visual elements inherent in Second Life" are "desirable because they reduce the social distance between subjects relative to traditional laboratory designs." (Al-Ubaidly et al. 2014: 46) Subjects have to decide how to allocate the initial endowment of natural resource income between rent-seeking pursuit, characterized by negative externality, and production activity, associated to positive externality. The virtual environment reproduces a spatial layout mimicking physical neighborhoods in which subjects' avatars can move around to chat with and to monitor other avatars' behavior. As postulated, in the treatment with communication and monitoring, assumed to be representative of high quality institutions, subjects play cooperatively by reducing rent-seeking and increasing production in response to a resource boom.

In another experiment, Twieg and Mc Cabe (2014) test the same condition - a virtual environment with chat and spatial monitoring - to investigate the conditions for efficient property rights systems in a common-pool renewable resources system. They use an open-source server platform to create a customized virtual world and a commons spatial environment in which heterogeneous natural resources (berries of different colors in virtual berry fields) can be harvested. The design includes the possibility of costly specialization in harvesting a specific color of berry, which maximizes income. The main finding is that communication, monitoring and specialization enhance the probability of creating efficient private property rights. Twieg and McCabe's design replicates Jansse and Ostrom's (2008) test in which that which subjects communicated face-to-face 
in a desktop simulation of a renewable resource environment. In both cases, participants use avatars, but in Twieg and McCabe's customized virtual world the introduction of virtual places and meeting areas clearly enhance participants' immersion and sense of presence.

How effectual spatial and temporal cues can be provided in virtual reality experiments is shown by Fiore et al. (2009), whose simulation of forest fires is aimed at investigating how subjects change their propensity to pay for fire prevention policies. With respect to previous experiments (Jude et al. 2006), their rendering enables subjects to change perspective on the visual environment by traveling across space and by moving back and forth in time within fire scenarios which developed according to a formal model. The comparison between virtual reality treatment and static treatment with 2-D time-shot images of the same fires allows estimating subjective parameters of risk and loss aversion and probability weights. Fiore et al. (2009) also submit a questionnaire on the sense of presence (Witmer et al. 2005) showing that subjects perceive high levels of involvement and immersion in the fire scenario. A similar approach is followed by Bateman et al. (2009), who implement a virtual reality experiment to elicit preferences for changes in coastal land use. In the main treatment, participants fly around and explore rendered areas built on the basis of actual geographic and topographic data, while in the control treatment the same identical lands are presented in numeric form (i.e., use types and hectares). In the virtual treatment users exhibit a lower difference between willingness to pay for gains and willingness to accept the corresponding loss, which supports the conclusion that the provision of virtual cues can temper the impact of judgment errors in assessing the attributes defining the good to be valued.

Evidence like this provides a good argument in favor of virtual reality experiments, which contrasts one of the basic tenet of laboratory methodology according to which the use of nonprofessional subjects and monetary incentives allows making subjects' innate characteristics largely irrelevant (Smith 1994). On the contrary, very often subjects - especially professional ones - take into the lab the preferences applied to real choices and stick to them with high probability. These biases or inclinations can override the incentive effect. Visual information and, more generally, labels provided in immersive environments can offer clues to increase the external validity of experiments with a minimal sacrifice of internal validity.

This effect can be further amplified in HIVE settings, where context and subjects' attention is totally under the control of the experimenter and the sense of immersion can be leveraged to increase the felling of presence. A first attempt in this direction is provided by De Horatius et al. (2015), which design an experiment in which subjects perform a sorting task on a virtual conveyor 
belt. They use a cave automatic virtual environment (CAVE), in which projectors are directed to five of the surrounding walls of a room-sized cube, users wear special glasses to perceive the threedimensional graphics and interface software synchronizes projected images with users' positions and movements. As a result, subjects experience full immersion while performing experimental tasks. This apparatus allows providing images of the products (virtual cubes of different colors to sort in virtual bins) to be sorted on the conveyor belt and visual cues helpful to improve sorting accuracy and productivity. Although this design represent a first attempt in the implementation of HIVE settings in experimental economics, evidence provided in cognitive psychology and social sciences (Sanchez-Vives and Slater 2005, Bainbridge 2007, Fox et al. 2009a, Cummings and Bailenson 2016) show that the highest degree of immersion allows experimenter to boost the external validity of experiments by increasing greatly the control of the experimental environment and task. The future research is bound to provide convincing evidence showing that also experimental economics can greatly benefits from using virtual reality.

\section{Conclusion}

The question that this paper has addressed is whether virtual reality is a suitable tool for conducting economic experiments. The literature surveyed above points out a number of pros and cons, but it also makes evident that the process of introduction of virtual reality in experimental economics is still in its early days. A full appraisal of its efficacy depends on the extensive use of high-immersive virtual environments, whose implementation is determined by the progress of virtual reality, which is still an emerging technology in the early stages of adoption.

The most evident advantages of virtual reality experiments are the practical ones. Today researchers can conduct experiments in virtual sceneries perfectly tailored to their purposes. Costs do not represent anymore a barrier to technology integration and it is easily predictable that virtual reality will be increasingly affordable in the near future. But the main pros pointed out by the surveyed literature are the efficacy of virtual reality as a tool to introduce contextual cues in experimental design under the full control of the experimenter. This element attenuates the contextfree illusion that represents an important limitation of the standard laboratory approach in economic and is hardly feasible in the field, where the realism of context is obtained at the expense of control and replicability. Moreover, in virtual reality subjects' perception of experimental settings can be handled and tested through the sense of presence, activated by the state of immersion experienced 
by subjects. Thus, it is not surprising that recent research emphasizes the importance of postexperimental surveys and questionnaires that measure the degree to which virtual environments engage participants' senses such as they are actively involved in experimental tasks. For what concerns findings, most research conducted in LIVE provides evidence that virtual reality experiments replicate the results obtained in standard laboratories. Some exceptions concern experiments on social interaction, which may be biased by the specific characteristics of virtual worlds. But this feature can also represent an asset, if it is considered that virtual worlds activate the sense of co-presence, which allows replicating and analyzing social interaction in vivo.

On the cons side, the main drawbacks of virtual reality experiments are virtual worlds' anonymity and the influence of digital identities. It is commonly assumed that virtual reality is associated to the escape from everyday experiences and real world. The artificiality of virtual communication and avatars' physical appearance may impact behavior in a way difficult to disentangle (Fox and Bailenson 2009, Fox et al. 2015). This effect can be reinforced by the gamelike atmosphere characterizing virtual worlds that may lead subjects to reject the experimental setting as irrelevant. To contrast this "rejection scenario" (Fiore et al. 2009: 72), it is helpful to design experiments that take advantage of the different degrees of immersion of virtual environments. LIVE are appropriate to test how individuals adjust the heuristics adopted in real settings and how they modify behavior, because the weaker sense of presence enhances mental readiness and facilitate the objectivity in evaluating virtual scenarios while weakening the effect of cognitive biases. In this perspective, a promising field of application of virtual reality experiments concerns the efficacy of empirical nudges, which are behavioral change interventions aimed at influencing choices by making use of flaws in individual decision-making. In LIVE the effect of such interventions can be analyzed by testing alternative incentives to modify behavior and by using avatars to elicit social responses (see Ahn 2015 for a survey on applications to health programs). The same approach can be applied to study experimentally intertemporal choice. Ersner-Hershfield et al. (2011) provide an interesting application by analyzing how virtual exposure to the future self can correct the hot-cold empathy gap (Loewenstein et al. 2003) and help decision makers to recognize the impact of cognitive biases. In contrast, the simulation of risky situations in HIVE can provide better evidence on how individuals react automatically and misperceptions are formed, being full immersion more appropriate to detect which types of context activate specific heuristics. These settings allow the investigation of how subjects react during an actual experience involving emotional engagement and response or automatically react to external factors otherwise neglected 
for lack of awareness. Once individuals experience a strong sense of immersion which conveys the feeling of being here, subjects can experience arousal and affect and adopt the heuristically driven behavior induced by the cues. By following these suggestions, probably the best approach to turn the novelty of Virtual Reality into an useful tool for economic experiments is not trying to build a bridge between the field and the lab, but to follow the same path on which experimental economics has been founded since its inception, that is to construct and test models of behavior in virtual reality to check if behavioral implications of these models fit what might be found in the real world.

\section{References}

Ahn, Sun Joo (Grace), 2015. "Using Avatars and Agents to Promote Real-World Health Behavior Changes." In Combs, Donald C., John A. Sokolowsky and Catherine M. Banks (Eds.), The Digital patient: Advancing Healthcare, Research, and Education, 171-180. New York: John Wiley.

Ahn, Sun Joo (Grace), Jesse Fox, Katherine R. Dale, and J. Adam Avant, 2015. "Framing Virtual Experiences: Effects on Environmental Efficacy and Behavior Over Time." Communication Research 42(6), 839-863.

Al-Ubaydli, Omar, Kevin McCabe, and Peter Twieg, 2014. Can More Be Less? An Experimental Test of the Resource Curse." Journal of Experimental Political Science 1(1), 39-58.

Anderhub, Vital, Rudolf Müller, and Carsten Schmidt, 2001. "Design and evaluation of an economic experiment via the Internet. " Journal of Economic Behavior \& Organization 46(2), 227-247.

Atlas, Stephen, 2008. "Inductive metanomics: economic experiments in virtual worlds. " Journal of Virtual Worlds Research 1(1), 1-15.

Atlas, Stephen and Louis Putterman, 2011. "Trust among the avatars: a virtual world experiment, with and without textual and visual cues. " Southern Economic Journal 78(1), 63-86.

Bainbridge, William Sims, 2007. "The scientific research potential of virtual worlds. " Science 317(5837), 472-476. 
Bateman, Ian J., Brett H. Day. Andrew P. Jones, and Simon Jude, 2009. "Reducing gain-loss asymmetry: A virtual reality choice experiment valuing land use change." Journal of Environmental Economics and Management 58(1), 106-118.

Bateson, Melissa, Daniel Nettle and Gilbert Roberts, 2006. "Cues of being watched enhance cooperation in a real-world setting. "Biology Letters 2(3), 412-414.

Biocca, Frank, Chad Harms, Judee K. Burgoon, 2003. "Toward a more robust theory and measure of social presence: review and suggested criteria." Presence 12( 5), 456-480.

Blascovich Jim, Jack Loomis, Andrew C. Beall, Kimberly R. Swinth, Crystal L. Hoyt, and Jeremy N. Bailenson, 2002. "Immersive virtual environment technology as a methodological tool for social psychology." Psychological Inquiry 13(2), 146-149.

Bloomfield, Robert, 2009. "World of Bizcraft." Journal of Virtual Worlds Research 2(3), 3-35.

Bloomfield, Robert J and Young Jun Choo, 2011. "Unregulated Stock Markets in Second Life." Southern Economic Journal 78(1), 6-29.

Camerer, Colin F. and George Loewenstein, 2004. "Behavioral economics: past, present and future." In Camerer, Colin F., George Loewenstein, and Matthew Rabin (Eds.), Advances in Behavioral Economics, 3-51. Princeton, NJ: Princeton University Press.

Castronova, Edward, Dmitri Williams, Cuihua Shen, Rabindra Ratan, Li Xiong, Yuan Huang, and Brian Keegan, 2009. "As real as real? Macroeconomic behavior in a large-scale virtual world. " New Media Society 11(5), 685-707.

Charness, Gary, Ernan Haruvy, and Doron Sonsino, 2007. "Social distance and reciprocity: An Internet experiment." Journal of Economic Behavior \& Organization 63(1), 88-103.

Charness, Gary and Matthias Sutter, 2012. "Groups make better self-interested decisions. " Journal of Economic Perspectives 26(3), 157-176.

Chesney, Thomas, Swee-Hoon Chuah, and Robert Hoffmann, 2009. "Virtual world experimentation: An exploratory study. " Journal of Economic Behavior \& Organization 72(1), 618-635.

Cummings, James J. and Jeremy N. Bailenson, 2016. "How immersive is enough? A meta-analysis of the effect of immersive technology on user presence." Media Psychology 19(2), 272-309. 
De Horatius, Nicole, Özgür Gürek, Dorothee Honhon, and Kyle B. Hyndman, 2015. "Understanding the Behavioral Drivers of Execution Failures in Retail Supply Chains: An Experimental Study Using Virtual Reality." Chicago Booth Research Paper N. 15-47. Available at SSRN: http://ssrn.com/abstract=2676628.

De Sousa, Yannick Ferreira and Alistair Munro, 2012. "Truck, barter and exchange versus the endowment effect: Virtual field experiments in an online game environment. " Journal of Economic Psychology 33(3), 483-493.

Duffy, John, 2011. "Trust in second life." Southern Economic Journal 78(1), 53-62.

Eckel, Catherine C. and Rick K. Wilson, 2006. "Internet cautions: experimental games with Internet partners." Experimental Economics 9(1), 53-66.

Ersner-Hershfield, Hal, Daniel G. Goldstein, William F. Sharpe, Jesse Fox, Leo Yeykelis, Laura L. Carstensen, and Jeremy N. Bailenson, 2011. "Increasing saving behavior through ageprogressed renderings of the future self. " Journal of Marketing Research 48(2), S23-S37.

Fiedler, Marina, 2009. "Cooperation in virtual worlds." Schmalenbach Business Review 61(2), 173194.

Fiedler, Marina and Ernan Haruvy, 2009. "The lab versus the virtual lab and virtual field: an experimental investigation of trust games with communication." Journal of Economic Behavior \& Organization 72(2), 716-724.

Fiedler, Marina, 2011. "Experience and Confidence in an Internet-Based Asset Market Experiment." Southern Economic Journal 78(1), 30-52.

Fiedler, Marina, Ernan Haruvy, and Sherry Xin Li, 2011. "Social distance in a virtual world experiment. " Games and Economic Behavior 72(2), 400-426.

Fiore, Stephen M., Glenn W. Harrison, Charles E. Hughes, and E. Elisabet Rütstrom, 2009. "Virtual experiments and environmental policy." Journal of Environmental Economics and Management 57(1), 65-86.

Fox, Jesse and Jeremy N. Bailenson, 2009. "Virtual self-modeling: The effects of vicarious reinforcement and identification on exercise behaviors." Media Psychology 12(1), 1-25.

Fox, Jesse, Dylan Arena and Jeremy N. Bailenson, 2009a. "Virtual reality: a survival guide for the social scientist." Journal of Media Psychology 21(3), 95-113. 
Fox, Jesse, Sun Joo Ahn, Joris H. Janssen, Leo Yeykelis, Kathryn Y. Segovia, and Jeremy N. Bailenson, 2015. "Avatars Versus Agents: A Meta-Analysis Quantifying the Effect of Agency on Social Influence." Human-Computer Interaction 30(5), 401-432

Füllbrunn, Sascha., Katharina Richwien, and Abdolkarim Sadrieh, 2011. "Trust and trustworthiness in anonymous virtual worlds." Journal of Media Economics 24(1), 48-63.

Gigerenzer, Gerd and Peter M. Todd, 1999. "Simple heuristics that make us smart. Evolution and cognition." New York, NY: Oxford University.

Greiner, Ben, Mary Caravella, and Alvin E. Roth, 2014. "Is avatar-to-avatar communication as effective as face-to-face communication? An Ultimatum Game experiment in First and Second Life." Journal of Economic Behavior \& Organization 108(C), 374-382.

Guala, Francesco, 2005. The Methodology of Experimental Economics. New York: Cambridge University Press.

Harrison, Glenn W. and John A List, 2004. "Field experiments." Journal of Economic Literature 42(4), 1009-1055.

Harrison, Glenn W., Ernan Haruvy, and E. Elisabet Rütstrom, 2011. "Remarks on virtual world and virtual reality experiments." Southern Economic Journal 78(1), 87-94.

Hertwig, Ralph and Andreas Ortmann, 2001. "Experimental practices in economics: a methodological challenge for psychologists? "Behavioral Brain Sciences 24(3), 383-403.

Jude, Simon, Andrew P. Jones, J.E. Andrews and Ian J. Bateman, 2006. "Visualisation for participatory coastal zone management: A case study of the Norfolk Coast, England. " Journal of. Coastal Research 22(6), 1527-1538.

Janssen, Marco A. and Elinor Ostrom, 2008. "TURFS in the Lab: Institutional Innovation in RealTime Dynamic Spatial Commons." Rationality and Society 20(4), 371-397.

Kahneman, Daniel and Amos Tversky, 1979. "Prospect Theory: An Analysis of Decision Under Risk." Econometrica 47(2), 263-291.

Kock, Ned, 2004. "The psychobiological model: Towards a new theory of computer-mediated communication based on Darwinian evolution." Organization Science 15(3), 327-348. 
Kugler, Tamar, Edgar E. Kausel, and Martin Kocher. 2012. "Are groups more rational than individuals? A review of interactive decision making in groups." WIREs Cognitive Science $3(4), 471-482$.

Lee, Younghwa., Kenneth A. Kozar, and Kai R. Larsen, 2009. "Avatar e-mail versus traditional email: Perceptual difference and media selection difference." Decision Support Systems 46(2), 451-467.

Levitt, Steven D. and John A. List, 2007. "Viewpoint: On the Generalizability of Lab Behaviour to the Field." The Canadian Journal of Economics 40(2), 347-370.

Loewenstein, George, 1999. "Experimental Economics From the Vantage-Point of Behavioural Economics." The Economic Journal 109(453), 25-34.

Loewenstein, George, Ted O’Donoghue, and Matthew Rabin, 2003. "Projection bias in predicting future utility." Quarterly Journal of Economics 118(4), 1209-1248.

Mennecke, Brian E., Janea L. Triplett, Lesya M. Hassall, Zayira Jordán Conde, and Rex Heer, 2011. "An Examination of a Theory of Embodied Social Presence in Virtual Worlds." Decision Sciences 42(2), 413-450.

Neumann, John von and Oskar Morgenstern, 1947. "Theory of Games and Economic Behavior." 2nd edition. Princeton (NJ): Princeton University Press.

Nicklisch, Andreas and Tobias Salz, 2008. "Reciprocity and status in a virtual field experiment." Preprints of the Max Planck Institute for Research on Collective Goods, N. 37. Available at: http://hdl.handle.net/10419/32225.

Sanchez-Vives, Maria V. and Mel Slater, 2005. "From presence to consciousness through virtual reality." Nature Reviews Neuroscience 6(4), 332-339.

Slater, Mel, Martin Usoh, and Anthony Steed, 1994. "Depth of presence in virtual environments. Presence." Teleoperators and Virtual Environments 3(2), 130-140.

Smith, Vernon L. 1962. "An Experimental Study of Competitive Market Behavior." The Journal of Political Economy 70(2), 111-137.

Smith, Vernon L. 1994. "Economics in the Laboratory." Journal of Economic Perspectives 8(1), $113-131$. 
Smith, Vernon L. 2003. "Constructivist and Ecological Rationality in Economics." American Economic Review 93(3), 465-508.

Spann, Martin, Oliver Hinz, Il-Horn Hann, and Bernd Skiera, 2010. "Decision Making in Virtual Worlds: An Experimental Test of Altruism, Fairness and Presence." Proceedings of the European Conference on Information Systems (ECIS). Available at: http://aisel.aisnet.org/cgi/viewcontent.cgi?article=1008\&context=ecis2010.

Twieg, Peter and Kevin McCabe, 2014. "The Determinants of Territorial Property Rights in a Spatial Commons Experiment." George Mason University, Department of Economics, WP N. 14-40. Available at SSRN: http://ssrn.com/abstract=2503260.

Witmer, Bob G., Christian J. Jerome, and Michael J. Singer, 2005. "The factor structure of the presence questionnaire." Presence 14(3), 298-312.

Yee, Nick and Jeremy Bailenson, 2007. "The Proteus Effect: The effect of transformed selfrepresentation on behavior." Human Communication Research 33(3), 271-290. 


\section{LabSi Working Papers \\ ISSN 1825-8131 (online version) 1825-8123 (print version)}

Issue
n. $1 / 2005$
n. $2 / 2005$
n. $3 / 2005$
n. $4 / 2005$

ก. $5 / 2006$

n. $6 / 2006$

ก. $7 / 2006$

n. $8 / 2006$

n. $9 / 2006$

Gerlinde Fellner

Erik Theissen

Robin Pope

n. $10 / 2006$

Reinhard Selten

Sebastian Kube

Jürgen von Hagen

$\begin{array}{ll}\text { n. 11/2006 } & \text { Niall O'Higgins } \\ \text { Patrizia Sbriglia }\end{array}$

Mauro Caminati

n. 12/2007 Alessandro Innocenti

Roberto Ricciuti

n. $13 / 2007$

Klaus Abbink

Jordi Brandts

n. $14 / 2007$
Jens Großer

Arthur Schram
Title

Law and Behaviours in Social Dilemmas: Testing the Effect of Obligations on Cooperation (April 2005)

Group Cooperation Under Alternative Peer Punishment Technologies: An Experiment (June 2005)

Social Learning in Market Games (June 2005)

Bringing Macroeconomics into the Lab (December 2005)

Altruism and Gender in the Trust Game (February 2006)

The power of words in financial markets:soft versus hard communication, a strategy method experiment (April 2006)

Financial Engineering and Rationality: Experimental Evidence Based on the Monty Hall Problem (April 2006)

The dynamics of trader motivations in asset bubbles (April 2006)

Short Sale Constraints, Divergence of Opinion and Asset Values: Evidence from the Laboratory (April 2006)

Experimental Evidence on the Benefits of Eliminating Exchange Rate Uncertainties and Why Expected Utility Theory causes Economists to Miss Them (May 2006)

Are Imitative Strategies Game Specific? Experimental Evidence from Market Games (October 2006)

Drift and Equilibrium Selection with Human and Virtual Players (April 2007)

Political Autonomy and Independence: Theory and Experimental Evidence (September 2007)

Public Opinion Polls, Voter Turnout, and Welfare:

An Experimental Study (September 2007) 

n. $15 / 2007$
Nicolao Bonini
Ilana Ritov
Michele Graffeo

n. 16/2007 Jaromir Kovarik

Vivian Lei

n. 17/2007 Steven Tucker

Filip Vesely

n. 18/2007 Jُoana Pais

Antonio Cabrales

n. 19/2007 Rosemarie Nagel José V. Rodrìguez Mora

n. $20 / 2008$

n. $21 / 2008$

n. $22 / 2008$

Alessandro Innocenti

Alessandra Rufa Jacopo Semmoloni

\section{Francesco Farina}

Niall O'Higgins

Patrizia Sbriglia

Carla Marchese

Marcello Montefiori

2008)

It is Hobbes not Rousseau: An Experiment on Social Insurance (September 2007)

Eliciting motives for trust and reciprocity by attitudinal and behavioural measures (June 2008)

Cognitive Biases and Gaze Direction: An Experimental Study (June 2008)

How do economists differ from others in distributive situations? (September 2008)

Can Sanctions Induce Pessimism? An Experiment (January 2009)

\section{Karl Schlag}

Roberto Galbiati

n. $24 / 2009$

Joël van der Weele

n. $25 / 2009$

n. $26 / 2009$

\section{Annamaria Nese}

Patrizia Sbriglia

Alessandro Innocenti Antonio Nicita

Individuals' Voting Choice and Cooperation in Repeated Social Dilemma Games (February 2009)

\section{Virtual vs. Standard Strike: An Experiment (June} 2009)

Alessandro Innocenti Patrizia Lattarulo Maria Grazia Pazienza

Heuristics and Biases in Travel Mode Choice (December 2009)

S.N. O'Higgins

n. 28/2010 Arturo Palomba

Patrizia Sbriglia

Valeria Faralla

n. $29 / 2010$
Second Mover Advantage and Bertrand Dynamic Competition: An Experiment (May 2010)

Gains and Losses in Intertemporal Preferences: A Behavioural Study (June 2010)
Francesca Benuzzi

Paolo Nichelli

Nicola Dimitri 
Angela Dalton

n. 30/2010 Alan Brothers

Stephen Walsh

Paul Whitney

n. 31/2010 Giuseppe Attanas

Aldo Montesano

n. $32 / 2010$

Georgios Halkias

Flora Kokkinaki

Valeria Faralla

Francesca Benuzzi

n. $33 / 2010$

Fausta Lui

Patrizia Baraldi

Paolo Nichelli

Nicola Dimitri

Jordi Brandts

Orsola Garofalo

n. 35/2011 Ladislav Čaklović

n. $36 / 2011$

Alessandro Innocenti Chiara Rapallini

Alessandro Innocenti

n. 37/2012 Tommaso Nannicini Roberto Ricciuti

Azzurra Ruggeri

n. $38 / 2012$

Konstantinos V.

Katsikopoulos

n. 39/2012 Lory Barile

Luigi Luini

n. 40/2012 Annamaria Nese

Patrizia Sbriglia
Expert Elicitation Method Selection Process and Method Comparison (September 2010)

The Price for Information about Probabilities and its Relation with Capacities (September 2010)

Attention, Memory, and Evaluation of Schema Incongruent Brand Messages: An Empirical Study (September 2010)

Gains and Losses: A Common Neural Network for Economic Behaviour (September 2010)

Gender Pairings and Accountability Effect (November 2010)

Conflict Resolution. Risk-As-Feelings Hypothesis. (January 2011)

Voting by Ballots and Feet in the Laboratory (January 2011)

The Importance of Betting Early (January 2012)

More Does Not Always Lead to Better: Mothers, Young Women, and Girls Generating Causes of a Baby Crying (February 2012)

Does tax evasion affect firms' internal control? Some evidence from an experimental approach (February 2012)

Social Influence in Trustors' Neighborhoods (July 2012) 
n. 41/2012 Simon Halliday

n. 42/2012 Enrica Carbone

Gerardo Infante

n. 43/2012 Enrica Carbone

Gerardo Infante

Francesco Feri

n. 44/2012 Alessandro Innocenti Paolo Pin

Jeffrey V. Butler

n. 45/2012 Enrica Carbone

Pierluigi Conzo

Giancarlo Spagnolo

Valeria Faralla

n. 46/2013 Alessandro Innocenti Eva Venturini

Valeria Faralla

n. $47 / 2013$

Alessandro Innocenti

Stefano Taddei

Eva Venturini

Niall O'Higgins

n. 48/2014 Arturo Palomba

Patrizia Sbriglia

n. 49/2015 Alessandro Innocenti
Taking, Punishment and Trust (August 2012)

Are Groups Better Planners Than Individuals? An

Experimental Analysis (December 2012)

The Effect of a Short Planning Horizon on Intertemporal Consumption Choices (December 2012)

Is There Psychological Pressure in Competitive Environments?(December 2012)

Reputation and Entry (December 2012)

Risk Taking and Social Exposure (July 2013)

Physiological Responses to Stressful Work Situations in Low-Immersive Virtual Environments (July 2013)

Gender Effects, Culture and Social Influence in the Dictator Game: An Italian Study (December 2014)

Virtual Reality Experiments in Economics (November 2015) 
LABSI WORKING PAPERS

ISSN 1825-8131 (ONLINE VERSION) 1825-8123 (PRINT VERSION)

LABSI EXPERIMENTAL ECONOMICS LABORATORY

UNIVERSITY OF SIENA

PIAZZA S. FRANCESCO, 753100 SIENA (ITALY)

http://www.labsi.org labsi@unisi.it 